\section{Identification and Cloning of Integration Site of DNA by PCR}

BioTechniques 20:356-358 (March 1996)

Exogenous DNA can be inserted into chromosomes by retroviral integration, transposon jumping, intrachromosomal translocations, as well as gene transfer techniques such as cell transfection assays and the preparation of transgenic animals. The sites of such insertions of exogenous DNA are usually identified by preparing genomic libraries and isolating clones containing both the exogenous DNA and flanking sequences $(4,6,7)$. The task of isolating the appropriate genomic clone is usually time-consuming and tedious. In some situations, the flanking sequences can be isolated rapidly by plasmid rescue in Escherichia coli (1) or by inverse polymerase chain reaction (IPCR) (5). These rescue procedures have limitations in that either the inclusion of plasmid sequences is required (1) or the knowledge of restriction enzymes sites close to the site of integration (5) is essential. Though IPCR is known as being a simple procedure, on the other hand it involves several steps such as digestion of genomic DNA with different restriction enzymes, followed by recircularization and digestion with another enzyme. Another limitation is that amplification of DNA may become difficult where the enzyme sites are separated by large DNA sequences. In this report we present a simple PCR-based method to clone the flanking chromosomal DNA at the site of insertion of foreign DNA.

In the first and key step, the chromosomal DNA at the junction of transgene insertion is enriched by repeated cycles of primer extension using a DNA polymerase and a primer specific for the transgene, thus extending it into the flanking chromosomal DNA (see Figure 1). This is followed by amplification of the DNA by PCR using several arbitrary primers, each separately and the same transgene-specific primer. The chromosomal:transgene junction fragments are identified by Southern blot analysis. The junction fragment is further amplified in a second round of PCR using a nested primer and the specific arbitrary primer, followed by cloning and sequencing.

Genomic DNA from a transgenic mouse that contained 1-2 copies of a human minigene for $\alpha 1$ collagen type I (COL1A1) (2) was subjected to 5 cycles of primer extension by Taq DNA Polymerase (Perkin-Elmer, Norwalk, CT, USA) at $94^{\circ} \mathrm{C}$ for $1 \mathrm{~min}, 50^{\circ} \mathrm{C}$ for 1 min, and $72^{\circ} \mathrm{C}$ for $1 \mathrm{~min}$, with $0.5 \mu \mathrm{M}$ concentration of primer $\mathrm{S} 1$ situated about $200 \mathrm{bp} 3^{\prime}$-end and to the $5^{\prime}$-end of the transgene (primer S1, Figure 1).
The primer-extended DNA was then amplified by PCR using the same primer (S1) and commercially available arbitrary primers (10-mers; Operon Technologies, Alameda, CA, USA) at $94^{\circ} \mathrm{C}$ for $30 \mathrm{~s}, 36^{\circ} \mathrm{C}$ for $30 \mathrm{~s}$, and $72^{\circ} \mathrm{C}$ for $30 \mathrm{~s}$ for 40 cycles in a PEC9600 thermal cycler (Perkin-Elmer). The amplified fragments were separated by electrophoresis on $1.5 \%$ NuSieve $^{\circledR}$ (FMC BioProducts, Rockland, ME, USA) and the $1.0 \%$ agarose gel (Life Technologies, Gaithersburg, MD, USA). Forty arbitrary primers were tested, each separately, for the amplifi-

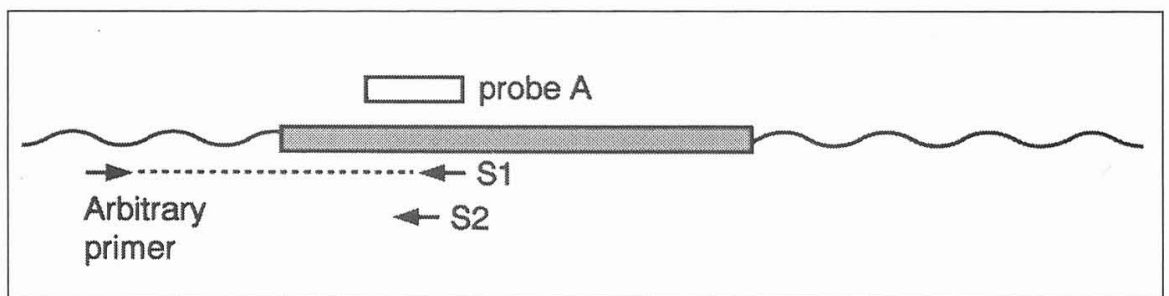

Figure 1. Schematic diagram of the method. Stippled bar, foreign DNA; thin line, chromosomal DNA; and the open box, probe specific for the transgene. The primers are represented by arrows.

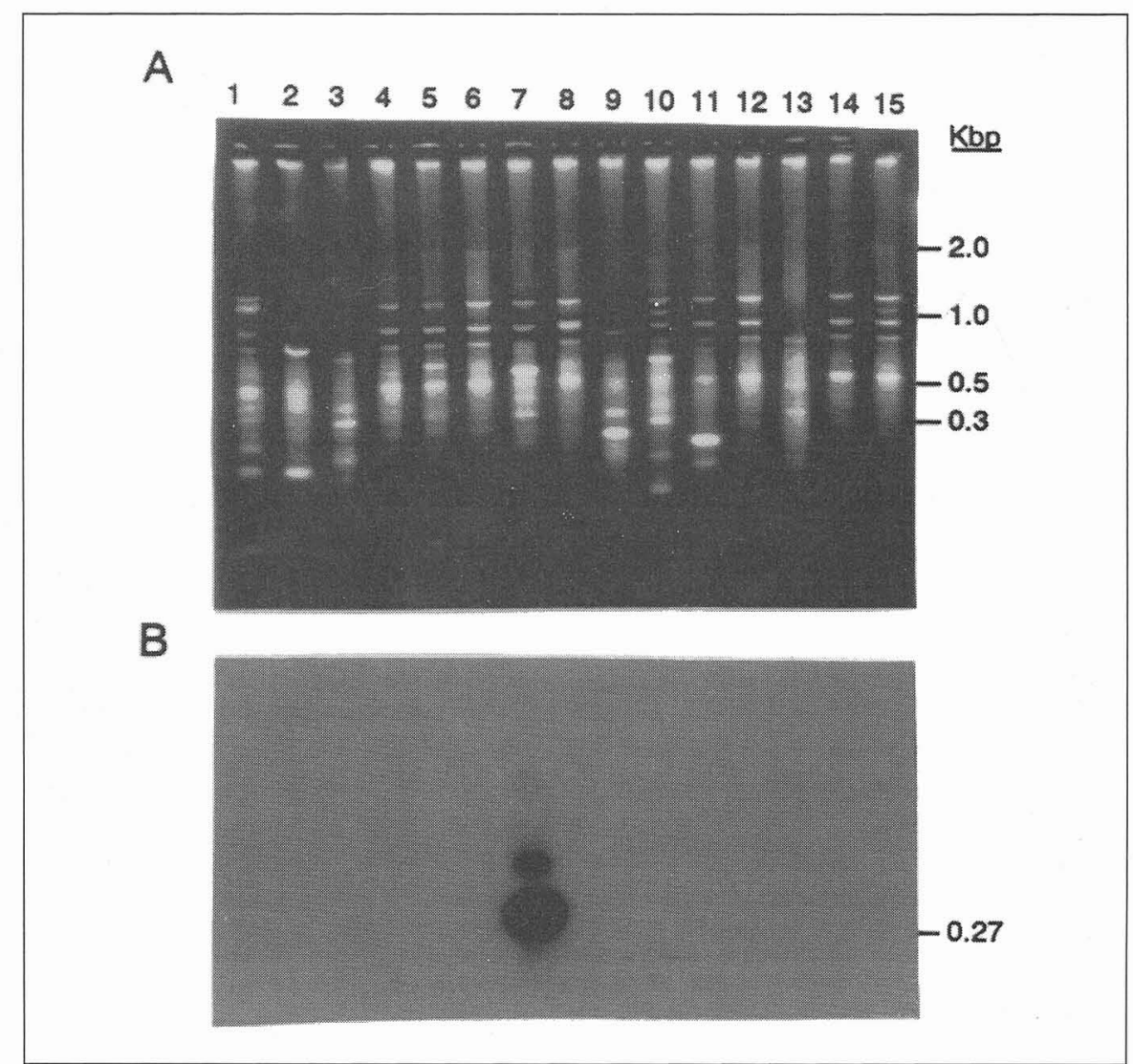

Figure 2. Panel A: PCR amplification of primer-extended DNA with 15 different arbitrary primers. Panel B: Southern blot analysis of the PCR-amplified DNA in Panel A with transgene-specific probe A (Figure 1). Lane 7 shows the hybridization of probe to bands of about 270 and $370 \mathrm{bp}$. 
cation of DNA with primer S1. Each arbitrary primer, apart from amplifying the transgene-specific fragment, may also amplify several random fragments of the genomic DNA. Figure 2A shows the gel electrophoresis pattern of amplified fragments with 15 separate arbitrary primers. To identify fragments that are specific for the transgene, the DNA was transferred onto nitrocellulose filters and analyzed by Southern blot analysis using $32 \mathrm{P}-1$ labeled transgene-specific probe (probe A, Figure 1) following the method described by Lee et al. (3). The blots were washed in $2 \times$ standard saline citrate (SSC) and $0.1 \%$ sodium dodecyl sulfate (SDS) at $68^{\circ} \mathrm{C}$ for $30 \mathrm{~min}$, followed by washing three times, 15 min each in $0.1 \times \mathrm{SSC}$ at $50^{\circ} \mathrm{C}$. Of the 40 arbitrary primers that were tested, 5 primers amplified 270-450-bp transgene-specific DNA fragments. Figure 2B shows the data for the amplification of DNA with 15 separate primers. Primer A-7 amplified two transgene-specific bands of about 270 and $370 \mathrm{bp}$, respectively (Figure 2B, lane 7). The area corresponding to each band was cut out from a replica gel and reamplified with nested primer S2, a 17-mer with approximately $50 \%$ $\mathrm{G}+\mathrm{C}$ content, and primer A-7 (Figure 1 ). Both bands amplified a single fragment of about $270 \mathrm{bp}$, suggesting that more than one sequence at the $5^{\prime}$-end of the site of integration is recognized by the same primer. However, it appears that the distal sequences failed to reamplify in the second PCR. The amplified

\section{GAAACGGGTGGCCAACAGTTCTCACAAATGC A-7 ACTGCATTTCCCCACTTCCAGGCCTTCTAGA ACTAGTG'GGCCGCGATCCCCAAATATCCTTCAGA ACCCCAGGCCCATGATGTAGCAACCCCCAATTCAC ACCTTGGAGGTTTCAACTCTTCTITAAGATGGGCG TGGGAAAGCCTGGATGGGAAACATATGGGGAGGGG CGGGGAGCTGCAGGCAGGAGCCTTCTTACTACGAA AACCCAAGAAGCAAGGAAGTGGACA $\mathrm{S2}$}

Figure 3. Sequence of the 270-bp PCR-amplified fragment. Unique chromosomal sequences are shown in bold letters. The junction of the chromosomal and foreign DNA is indicated by an arrow. The positions of arbitrary primer A-7 and the transgene-specific primer $\mathrm{S} 2$ are underlined. band was cloned into a TA Cloning ${ }^{\mathrm{TM}}$ Vector (Invitrogen, San Diego, CA, USA) and sequenced by the dideoxy sequencing method (Figure 3). The sequence comparison of amplified DNA revealed that this fragment represented $200 \mathrm{bp}$ of the transgene and $70 \mathrm{bp}$ of unique mouse genomic sequences at the integration site (Figure 3). The junction of transgene and chromosomal DNA is marked with an arrow, and the unique chromosomal sequences are shown in bold letters. Similar experiments with DNA from another transgenic mouse line with multiple copies of transgene identified sequences spanning the junction of two copies of the transgene, as well as sequences at the junction of transgene with chromosomal DNA (data not shown).

The method described here involves techniques that are routinely used in any molecular biology laboratory. The unique sequences identified by this method can be used directly to scan the DNA databases or to screen the genomic libraries to identify novel genes. Alternatively, the sequence can be used to identify further upstream or downstream flanking sequences by repeating the whole procedure with the primers specific for these sequences. Since this procedure involves an initial step of enrichment of sequences by primer extension at the chromosomal junction site, the problems associated with the detection of single-copy sequences are reduced. Furthermore, the procedure also provides the flexibility of cloning the flanking chromosomal sequences at either end of the foreign DNA by using primers for both ends of the transgene (5). Although not tested here, the method may be applicable for cloning the sites of viral integration and transposable elements. Another important application may be to identify the junctions of the intrachromosomal translocations, where partial information of the translocated gene is available.

\section{REFERENCES}

1.Grant, S.G.N., J. Jessee, F.R. Bloom and D. Hanahan. 1990. Differential plasmid rescue from transgenic mouse DNAs into $E s-$ cherichia coli methylation-restriction mutants. Proc. Natl. Acad. Sci. USA 87:4645-4649.
2.Khillan, J.S., A.S. Olsen, K. Kontusaari, B. Sokolov and D.J. Prockop. 1991. Transgenic mice that express a mini-gene version of the human gene for type I procollagen (COL1A1) develop a phenotype resembling a lethal form of osteogenesis imperfecta. J. Biol. Chem. 266:23373-23379.

3.Lee, F-J.S., J. Moss and L-W. Lin. 1992. A simplified procedure for hybridization of RNA blots. BioTechniques 13:844-846.

4.Schnieke, A., K. Harbers and R. Jaenisch. 1983. Embryonic lethal mutation in mice induced by retrovirus insertion into the $\alpha 1$ (I) collagen gene. Nature 304:316-320.

5.Triglia, T., M.G. Peterson and D.J. Kemp. 1988. A procedure for in vitro amplification of DNA segments that lie outside the boundaries of known sequences. Nucleic Acids Res. 16:8186.

6.Woychick, R.P., T.A. Stewart, L.G. Donis, P. D'Eustachio and P. Leder. 1985. An inherited limb deformity created by insertional mutagenesis in a transgenic mouse. Nature 318:36-40.

7.Yokoyama, T., N.G. Copeland, N.A. Jenkins, C.A. Montgomery, F.F.B. Elder and P.A. Overbeek. 1993. Reversal of left-right asymmetry: a situs inversus mutation. Science 260:679-682.

We thank Ms. Machiko Arita for technical assistance. This work was supported by NIH Grant AR38188. Address correspondence to Jaspal S. Khillan, Department of Biochemistry and Molecular Biology, Jefferson Medical College, Thomas Jefferson University, 233 South Tenth Street, Philadelphia, PA 19107, USA.

Received 24 May 1995; accepted 20 September 1995.

Shi-Wu Li, Kaye Marie Nembhard, Darwin J. Prockop and Jaspal S. Khillan Jefferson Medical College Thomas Jefferson University Philadelphia, PA, USA 